\title{
Prevalence and Factors Affecting Irritable Bowel Syndrome Among Medical Students at Taibah University
}

\author{
Imtinan Al-bukhari", Khaled Al-Malki, Mohammed Kashkari, Amal Alrifai, Moneer Adnan \\ College of Medicine, Taibah University, Madinah, Saudi Arabia \\ Email address: \\ Imtinan.Albukhari@gmail.com (I. Al-bukhari),kakamalki@gmail.com (K. Al-Malki), Moh_kashkari@hotmail.com (M. Kashkari), \\ Amal.m.alrifai@gmail.com (A. Alrifai), Moneer.adnan18@gmail.com (M. Adnan) \\ ${ }^{*}$ Corresponding author
}

\section{To cite this article:}

Imtinan Al-bukhari, Khaled Al-Malki, Mohammed Kashkari, Amal Alrifai, Moneer Adnan. Prevalence and Factors Affecting Irritable Bowel Syndrome Among Medical Students at Taibah University. Clinical Medicine Research. Vol. 5, No. 1, 2016, pp. 1-5. doi: $10.11648 /$ j.cmr.20160501.11

Received: March 12, 2016; Accepted: March 21, 2016; Published: April 1, 2016

\begin{abstract}
Background: The stressful life of medical students may worsen the symptoms of irritable bowel syndrome, which is a chronic common disorder of the large intestine. In Saudi Arabia, chronic diseases are considered the cause for $69 \%$ of all deaths in 2002. Objectives: to identify the prevalence of chronic diseases, especially the prevalence of IBS among medical students at the University, and also to identify the risk factors contributing to IBS. Methods: A community-based Observational study was conducted among 555 students at the College of Medicine at the University over the period $1-29$ May 2014. A self-administered questionnaire was used to collect data from all subjects included in the study. Results: The prevalence of Irritable bowel at the University was $10.5 \%$. It was more prevalent in senior students reaching a peak in 5 th year $(16.8 \%)$ $(\mathrm{p}=0.022)$. There was significant relationship between IBS and students who have low socioeconomic status and low grades (GBA). Other chronic diseases were less in medical students than the general population in Saudi Arabia. Conclusion: The study illustrated a high prevalence of IBS among medical students at the University, so we recommend a structured program for stress management among students including sports and recreational facilities that are geared to reduce stress and prevent it from reaching pathological states.
\end{abstract}

Keywords: Irritable Bowel Syndrome, Factors, Medical Student, Prevalence

\section{Introduction}

Irritable bowel syndrome (IBS) is a common disorder of the large intestine and one of the chronic diseases that may become worse by stress [1]. The stressful life of medical students may worsen the symptoms of irritable bowel syndrome, and depending on this fact we predict that the symptoms of IBS may increase in senior medical students compared to younger students due to the increasing levels of stress of work and study. Students living away from their families may have higher rates of IBS due to stress and emotional liability.

Other than the emotional problems, age and sex are also factors affecting the IBS as it's more prevalent in adolescent females, also food sensitivity and some medications can contribute to IBS. [2]
The prevalence rate of IBS in the world is from 9-23\% [3]. In Saudi Arabia the disease shouldn't be underestimated, because it can cause serious economic problems as IBS patients need more tests, more physicians' consultations, more medications and even more surgical interventions. [4]

Other chronic diseases that we presented in this survey are diabetes mellitus (DM), hypertension, bronchial asthma, anemia and visual problems.

Chronic diseases are long-term conditions that we are able to control only, and generally there is no cure from chronic diseases [5].

In Saudi Arabia, chronic diseases are considered the cause for $69 \%$ of all deaths in 2002. One of the most important causes of chronic disease is the raised body mass index (BMI) leading to overweight and obesity [6]. As stated with IBS, stress also can be a common risk factor of chronic diseases. 
These stress factors may also lead the medical students to practice unhealthy lifestyle such as neglecting their diet of healthy meals, which may subsequently lead to some chronic diseases like anemia.

In other words, anemia is a sign of both poor nutrition and poor health. It has been associated with impaired daily activities; decrease in the exercise capacity, impaired cognitive function and may lead to some behavioral disturbances [7], thus anemia has been listed as a worldwide concern, that in May2002 the General Assembly of the United Nations produced a report on the importance of controlling this condition [8].

In general, the prevalence of chronic diseases increases with time, for example the global burden of DM type 2 will expand in 2030 from 171 million to 366 million patients [9].

On the other hand, some data of chronic diseases as asthma are not widely available in developing countries. But the availability of such data is important for epidemiological purposes, and also for determining the pharmaco-economic range of asthma in each society [10].

Visual problems (including refractive errors) and hypertension are also common diseases that warrant further research and studies. Identifying their prevalence can be useful for epidemiological and pharmaco-economical purposes.

The objectives of this study are to identify the prevalence of chronic diseases, specially the prevalence of IBS among medical students at the University, and also to identify the risk factors contributing to IBS.

\section{Material \& Methods}

\subsection{Population}

A community-based Observational study was conducted among the students of the College of Medicine at the University over the period $1-29$ May 2014. Ethical
Approval was obtained from the University's Administration. The study conformed to Helsinki Declaration of Human Rights. Criteria for inclusion in the study were all registered full time students at the College of Medicine of both genders and all ages, who were able to give an explicit consent to participate in the study. Students who were unable or unwilling to participate were excluded. The data was entered using the Statistical Package for Social Sciences (SPSS) version 18.0. chi square test and student $\mathrm{T}$ test were used for categorical and numerical data respectively.

\subsection{Questionnaire}

A self-administered questionnaire was used to collect data from all subjects included in the study. The questionnaire was in English and consisted of several sections including demographic, personal and socioeconomic data, as well as personal habits. Details of current and past medical conditions and health related difficulties were documented. The questionnaire included and introduction clearly outlining the objectives of the survey. Agreeing to complete the survey implied a consent to participate in the study. Some students completed a paper-based written questionnaire while others completed an identical electronic survey via Google Docs.

\section{Results}

The study was completed in 555 students who were enrolled at the College of Medicine at the University in the Academic year 2014/2015. The response rate of the questionnaire was $97.3 \%$. There was a total of 261 males and 294 females, with a mean age of $21.841 \pm 1.64$ (SD).

The prevalence of chronic diseases explored in this study is illustrated in Table 1. We have investigated diabetes, hypertension, bronchial asthma, visual problems and IBS in both male and female sectors. Figure 1 shows details of the distribution of these diseases among students.

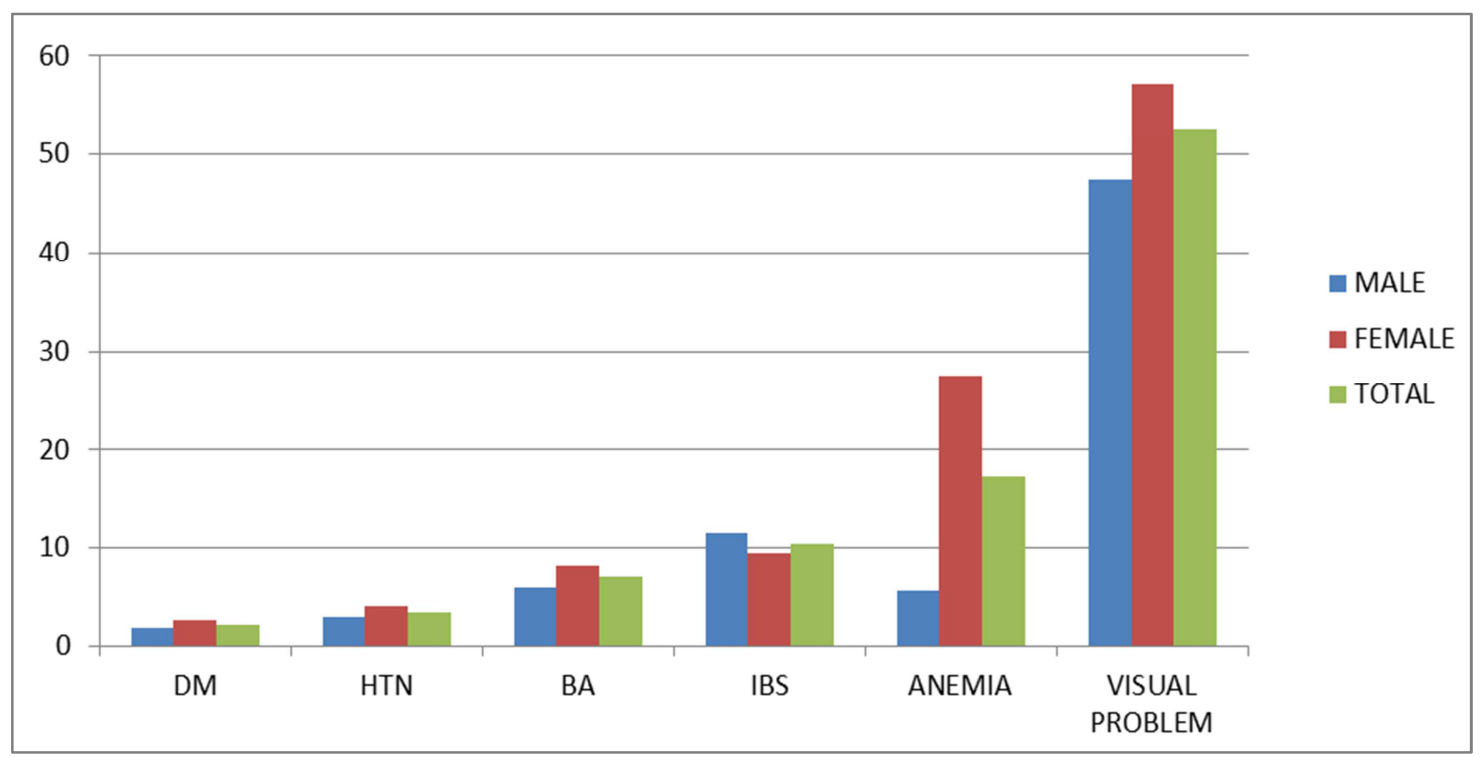

Figure 1. Percentage of chronic diseases among medical students at the university. 
We found a significant relationship between IBS and socio-demographic factors (Table 2). Students with a GPA of 'Excellent' were 8\%, 'Very good' $8.4 \%$, 'Good' $15.7 \%$ and 'Fair' $28.6 \%$ with a $\mathrm{P}=0.012$. Students in their 1 st year were $3.4 \%$, 2nd year $10.1 \%$, 3rd year $9.8 \%$, 4 th year $12.4 \%$ and 5 th year $16.8 \%$ with a $P$ value of 0.022 . Students who had a Family income $<5000$ S.R. were (23.3\%), 5000-10000 S.R. $(8.1 \%)$ and $>10000$ S.R. (10.3\%) with a $P$ value of 0.46 .

There was no significant statistical difference between students with IBS and other aspects of lifestyle. For example fast food per week $(p=0.400)$, soft drink per week $(p=0.529)$, number of meals per day $(p=0.289)$, energy drink $(p=0.480)$, number of sport practice $(\mathrm{p}=0.727)$, study hour per day $(\mathrm{p}=$ $0.726)$ duration of sleep $(\mathrm{p}=0.905)$ and smoking $(\mathrm{p}=0.776)$ (Table 3)

Table 1. Prevalence of chronic diseases among medical students at the university according to gender.

\begin{tabular}{lllllll}
\hline \multirow{2}{*}{$\begin{array}{l}\text { Chronic } \\
\text { disease }\end{array}$} & Total & \multicolumn{3}{c}{ Female } & \multicolumn{3}{c}{ Male } \\
\cline { 2 - 7 } & Number & \% & Number & \% & number & \% \\
\hline DM & 5 & 1.9 & 8 & 2.7 & 13 & 2.3 \\
HTN & 8 & 3.1 & 12 & 4.1 & 20 & 3.6 \\
BA & 16 & 6.1 & 24 & 8.2 & 40 & 7.2 \\
IBS & 30 & 11.5 & 28 & 9.5 & 58 & 10.5 \\
ANEMIA & 15 & 5.7 & 81 & 27.6 & 96 & 17.3 \\
Visual & 127 & 47.5 & 168 & 57.1 & 292 & 52.6 \\
problems & & & & & &
\end{tabular}

Table 2. IBS relation with socio-demographic factors.

\begin{tabular}{|c|c|c|c|c|c|}
\hline \multirow{3}{*}{ Variables } & & \multicolumn{4}{|l|}{ IBS } \\
\hline & & \multicolumn{2}{|l|}{ YES } & \multicolumn{2}{|l|}{ NO } \\
\hline & & NUMBER & $\%$ & NUMBER & $\%$ \\
\hline \multirow{2}{*}{ Gender } & Male & 30 & 11.5 & 231 & 88.5 \\
\hline & Female & 28 & 9.5 & 266 & 90.5 \\
\hline \multirow{6}{*}{ GBA } & P. value & .449 & & & \\
\hline & Excellent & 15 & 8.0 & 172 & 92.0 \\
\hline & Very good & 19 & 8.4 & 208 & 91.6 \\
\hline & Good & 20 & 15.7 & 107 & 84.3 \\
\hline & Fair & 4 & 28.6 & 10 & 71.4 \\
\hline & P. value & .012 & & & \\
\hline \multirow{3}{*}{$\begin{array}{l}\text { Social } \\
\text { status }\end{array}$} & Married & 7 & 18.4 & 31 & 81.6 \\
\hline & Single & 51 & 9.9 & 466 & 90.1 \\
\hline & p. value & .096 & & & \\
\hline \multirow{6}{*}{$\begin{array}{l}\text { Academic } \\
\text { level }\end{array}$} & $1^{\text {st }}$ year & 4 & 3.4 & 112 & 96.6 \\
\hline & $2^{\text {nd }}$ year & 12 & 10.1 & 107 & 89.9 \\
\hline & $3^{\text {rd }}$ year & 10 & 9.8 & 92 & 90.2 \\
\hline & $4^{\text {th }}$ year & 13 & 12.4 & 92 & 87.6 \\
\hline & $5^{\text {th }}$ year & 19 & 16.8 & 94 & 83.2 \\
\hline & p. value & .022 & & & \\
\hline \multirow{4}{*}{$\begin{array}{l}\text { Family } \\
\text { income }\end{array}$} & $<5000$ S.R & 7 & 23.3 & 23 & 76.7 \\
\hline & 5000-10000 S.R & 11 & 8.1 & 125 & 91.9 \\
\hline & $>10000$ & 40 & 10.3 & 349 & 89.7 \\
\hline & P. value & .046 & & & \\
\hline \multirow{4}{*}{ Age } & & \multicolumn{2}{|l|}{ MEAN } & \multicolumn{2}{|l|}{$\begin{array}{l}\text { STANDER } \\
\text { DEVIATION }\end{array}$} \\
\hline & Yes & \multicolumn{2}{|l|}{22.6} & \multicolumn{2}{|l|}{1.7} \\
\hline & No & \multicolumn{2}{|l|}{21.7} & \multirow{2}{*}{\multicolumn{2}{|c|}{1.5}} \\
\hline & P. value & .000 & & & \\
\hline
\end{tabular}

Table 3. IBS relationship with lifestyle.

\begin{tabular}{|c|c|c|c|c|c|}
\hline \multirow{3}{*}{ Fast food } & & \multicolumn{4}{|l|}{ IBS } \\
\hline & & \multicolumn{2}{|l|}{ Yes } & \multicolumn{2}{|l|}{ No } \\
\hline & & Number & $\%$ & number & $\%$ \\
\hline \multirow{4}{*}{ Per week } & None or Once & 15 & 8.1 & 171 & 91.9 \\
\hline & 2-3 times & 28 & 11.1 & 225 & 88.9 \\
\hline & 4-5 times & 9 & 11.1 & 72 & 88.9 \\
\hline & $>5$ & 6 & 17.1 & 29 & 82.9 \\
\hline \multirow[t]{2}{*}{ p. value } & & .400 & & & \\
\hline & None or Once & 21 & 10.9 & 171 & 89.1 \\
\hline \multirow{3}{*}{$\begin{array}{l}\text { Soft drink } \\
\text { per week }\end{array}$} & 2-3 times & 18 & 10.1 & 160 & 89.9 \\
\hline & 4-5 times & 6 & 6.8 & 82 & 93.2 \\
\hline & $>5$ & 13 & 13.4 & 84 & 86.6 \\
\hline \multirow[t]{2}{*}{ p. value } & & .529 & & & \\
\hline & 1 & 4 & 13.8 & 25 & 86.2 \\
\hline \multirow{3}{*}{$\begin{array}{l}\text { Number } \\
\text { of meals }\end{array}$} & 2 & 20 & 7.8 & 236 & 92.2 \\
\hline & 3 & 27 & 12.2 & 194 & 87.8 \\
\hline & $>3$ & 7 & 14.3 & 42 & 85.7 \\
\hline \multirow[t]{2}{*}{ p. value } & & .289 & & & \\
\hline & Never & 39 & 11.6 & 297 & 88.4 \\
\hline \multirow{4}{*}{$\begin{array}{l}\text { Energy } \\
\text { drink }\end{array}$} & Rarely & 12 & 7.6 & 145 & 92.4 \\
\hline & Often & 5 & 10.2 & 44 & 89.8 \\
\hline & Most & 1 & 10.0 & 9 & 90.0 \\
\hline & All time & 1 & 33.3 & 2 & 66.7 \\
\hline p. value & & .480 & & & \\
\hline \multirow{4}{*}{$\begin{array}{l}\text { Number of } \\
\text { sport } \\
\text { practice }\end{array}$} & None & 29 & 11.6 & 222 & 88.4 \\
\hline & Once a week & 17 & 10.7 & 142 & 89.3 \\
\hline & 2-3 a week & 8 & 9.3 & 78 & 90.7 \\
\hline & $>3$ a week & 4 & 6.8 & 55 & 93.2 \\
\hline \multirow[t]{2}{*}{ P. value } & & .727 & & & \\
\hline & $<2$ hour & 24 & 9.3 & 234 & 90.7 \\
\hline \multirow{3}{*}{$\begin{array}{l}\text { Study hour } \\
\text { per day }\end{array}$} & 2-4 hour & 23 & 12.5 & 161 & 87.5 \\
\hline & 4-6 hour & 9 & 10.1 & 80 & 89.9 \\
\hline & $>6$ hour & 2 & 8.3 & 22 & 91.7 \\
\hline \multirow[t]{2}{*}{ p. value } & & .726 & & & \\
\hline & $<3$ hour & 1 & 20.0 & 4 & 80.0 \\
\hline \multirow{3}{*}{$\begin{array}{l}\text { Duration } \\
\text { of sleep }\end{array}$} & 3-5 hour & 1 & 11.0 & 89 & 89.0 \\
\hline & 5-7 hour & 32 & 10.1 & 285 & 89.0 \\
\hline & $>7$ hour & 14 & 10.5 & 119 & 89.5 \\
\hline \multirow[t]{2}{*}{ p. value } & & .905 & & & \\
\hline & Yes & 7 & 10.3 & 61 & 89.7 \\
\hline \multirow[t]{2}{*}{ Smoking } & No & 49 & 10.3 & 426 & 89.7 \\
\hline & Ex-smoker & 2 & 16.7 & 10 & 83.3 \\
\hline p. value & & .776 & & & \\
\hline
\end{tabular}

\section{Discussion}

The prevalence of Irritable bowel syndrome at the University was $(10.5 \%)$ contrary to another study that was carried out in Jeddah. The prevalence and predictors of irritable bowel syndrome among medical students and interns at King Abdulaziz University showed that the prevalence of IBS was (31.8\%) [11]. Little information about its prevalence in Arab countries.

The prevalence of irritable bowel syndrome (IBS) was high in medical student compared to the general population, because it is related to stress and medical student have stressful lifestyle in the form of several assessments and 
examination for theoretical and practical subjects, long working and studying hours and less hours of sleep. We did not find any statistical difference in IBS between males $(11.5 \%)$ and females $(9.5 \%)(\mathrm{p}=.449)$.

IBS was more prevalent in students who are of low socioeconomic status (their families income $<5000$ S.R) $(p=0.046))$. It would be expected that students of low socioeconomic status are more likely to face higher levels of stressful life, bowel disorders and inappropriate diet that may explain the higher prevalence in this group of students. The study showed that the prevalence of IBS was high in students with low GPA $(p=.012)$. It was more prevalent in senior students reaching a peak in 5 th year $(16.8 \%)(p=0.022)$ and this is probably because of the increasing load of work, studying and responsibilities. The rate IBS was more than double in married students $(18.4 \%)$ compared to singles $(9.9 \%)$ but the difference was not statistically significant $(p=0.096)$. This funding was rather surprising as we would expect married students are likely to be more comfortable in their lifestyle, as they have partners who take care of them and support them emotionally.

There was no supporting evidence that IBS is worse in relation to daily meals, participation in sport, and number of sleeping hours, smoking or number of daily study hours.

Other chronic disease such as diabetes mellitus, hypertension, asthma, anemia and visual problems are common in Saudi Arabia, but their prevalence in Almadinah Almunawwarah has not been fully explored or documented in epidemiological studies especially among medical students.

In this study, the prevalence of chronic disease in medical students of the University was found to be lower than most of other studies conducted in Saudi Arabia and in particular Almadinah Almunawwarah.

The prevalence of diabetes mellitus was found to be $2.3 \%$ of the total student population at the university $(1.9 \%$ in males and $2.7 \%$ in females). This is significantly different than a previous study which showed that $23.1 \%$ of the population have the disease according to cohort study in Riyadh of 9,149 adult Saudis ages seven to eighty years [12]. Another study conducted in the years 2001-2007 for prevalence of type 1 diabetes in Saudi Arabian children and adolescents confirmed that the prevalence rate was 109.5 per 100,000 , with male to female ratio was almost equal [13].

Hypertension prevalence in this study was $(3.6 \%)$ in total. A study was done in 2007 showed that the prevalence of hypertension in Saudi Arabia was $(26.1 \%)$ in crude terms. For males, the prevalence of hypertension was $(28.6 \%)$ while for female the prevalence was significantly lower at $(23.9 \%)$ $(\mathrm{p}<0.001)$ [14].

For bronchial asthma the prevalence was (7.2\%) in total, which was lower than previously reported in Al Madinah $\mathrm{Al}$ Munawwarah in 2012. The prevalence of Allergic Disorders among primary school aged children was $23.6 \%$ [15].

Anemia is a common disease and it is more common in females because of many factors including menses. The current study showed the prevalence of anemia was $(17.3 \%)$ in total. Anemia and nutritional status of school children living in high altitude area were studied in 2006. The prevalence of anemia in this group was $(9.8 \%)$ [16].

Visual problems are very common in medical students as it is affecting more the half of them (52.6\%). The problems included Astigmatism, Farsightedness, Myopia and Color Vision Deficiency. There are no local studies to compare with. However, a recent study showed the prevalence of refractive errors was in one third of people who are older than 40 in United States, Western Europe and one fifth of Australians in this age group [17].

The strength of this study was that it addressed a major health issue among a large sample of the student population. It identified major diseases that affect student's welfare, therefore their educational attainment. It was hoped that the University's administration would consider the recommendations to implement programs to reduce the stress levels among students therefore enhancing their learning capabilities.

The major weakness of the study was in the design as it relied on self-reported questionnaire which was completed by students at all grades. There was no mechanism to objectively verify the accuracy of the information included in the analysis. This could be an opportunity to call for further research on a wider sample including all students of other colleges with some verification of the provided information.

\section{Conclusion and Recommendation}

The study illustrated a high prevalence of IBS among medical students at the University. As it related to stress there was high prevalence in low socioeconomic status as well as senior students and those who have achieved a low GBA. For these reasons, we recommend a structured program for stress management among students including sports and recreational facilities that are geared to reduce and prevent stress of reaching any pathological states. The prevalence of other chronic diseases was low except for the anemia which was high especially in females. There is a need to increase public awareness of common and chronic diseases and their risk factors. Public education and lifestyle modification programs may contribute to controlling chronic diseases.

\section{Acknowledgments}

First of all, we are grateful to our University for establishing us to complete this research paper. We would like to acknowledge all medical students and interns who participate in the research. As we would like to thank all administrative personnel who facilitated conditions for the work. We would like to express our sincere thanks and gratitude to Professor Imad Al-Khawaja of the Department of Medicine at Taibah University for his advice and supervision in the interpreting of the results and preparation of this manuscript. 


\section{References}

[1] Whitehead WE, Palsson O, Jones KR, Systemic review of the comorbidity of irritable bowel syndrome with other disorders: what are the causes and implications? Gastroenterology. 2002; 122: 1140-1156. [Pubmed].

[2] Irritable Bowel Syndrome (IBS) Health Center. pubmed. http://www.webmd.com/ibs/who-at-risk-ibs (Accessed 201501-09).

[3] International foundation for functional gastrointestinal disorder. http://www.aboutibs.org/site/what-is$\mathrm{ibs/facts/statistics} \mathrm{(Accessed} \mathrm{2015-1-9).}$

[4] Hulisz D. The burden of illness of irritable bowel syndrome: Current challenges and hope for the future. J Manag Care Pharm 2004; 10: 299-309.

[5] Pinhas-Hamiel O, Newfield R, Koren I, Agmen A, Lilos P, Philip M (2003) Greater prevelance of iron deficiency in overweight andobese children and adolescents. Int $\mathrm{J}$ ObesRelatMetab Disord 27: 416-418.

[6] World Health Organization, WHO (2008) Global database on anemia. In: de Benoist B, McLean E, Egli I, Cogswell M (eds) Worldwide prevalence of anemia (1993-2005). WHO, Geneva.

[7] University of Michigan, Center for Managing Chronic Disease, 1415 Washington Heights Ann Arbor, 2011.

[8] World health organization. Chronic diseases and health promotion http://www.who.int/chp/chronic_disease_report/en/ (Accessed 2014-12-18).

[9] Wild S, Rogli G, Green A, Sicree R, King H: Global prevalence of diabetes: estimates for the year 2000 and projections for 2030.Diabetes Care2004, 27: 1047-1053.
[10] Burney P, Chinn S, Jarvis D, Luczynska C, Lai E. Variationsin the prevalence of respiratory symptoms, self-reported asthma attacks anduse of asthma medication in the European Community Respiratory Health Survey (ECRHS). Eur Respir J 1996; 9: 687^695.

[11] Ibrahim, Nahla Khamis Ragab, Wijdan Fahad Battarjee, and Samia Ahmed Almehmadi. "Prevalence and predictors of irritable bowel syndrome among medical students and interns in King Abdulaziz University, Jeddah." Libyan Journal of Medicine 8.1 (2014).

[12] Al-Daghri, Nasser M., et al. "Diabetes mellitus type 2 and other chronic non-communicable diseases in the central region, Saudi Arabia (Riyadh cohort 2): a decade of an epidemic." BMC medicine 9.1 (2011): 76.

[13] Al-Herbish, Abdullah S., et al. "Prevalence of type 1 diabetes mellitus in Saudi Arabian children and adolescents." Saudi medical journal 29.9 (2008): 1285-1288.

[14] Mansour M. Al-Nozha, FRCP; Ali K. Osman, PhD Annals of Saudi Medicine, Vol 18, No 5, 1998401.

[15] Nahhas M, Bhopal R, Anandan C, Elton R, Sheikh A (2012) Prevalence of Allergic Disorders among Primary School-Aged Children in Madinah, Saudi Arabia: Two-Stage CrossSectional Survey. PLoS ONE 7(5): e36848. doi: 10.1371/journal.pone.0036848.

[16] Alaa H Abouzeid, anemia and nutritional status of schoolchildren living at Saudi high altitude area, 862, Saudi med j 2006, vol. 27 (6): 862-869.

[17] The Prevalence of Refractive Errors Among Adults in the United States, Western Europe, and Australia, Arch Ophthalmol. 2004; 122: 495-505. 